\title{
Analisis Tegangan pada Penegar Wrang Pelat Akibat Kemiringan Penegar Wrang Pelat
}

\author{
Robertus Bimo Pamungkas Sukoco, Wing Hendroprasetyo Akbar Putra, dan Septia Hardy Sujiatanti \\ Departemen Teknik Perkapalan, Fakultas Teknologi Kelautan, Institut Teknologi Sepuluh Nopember (ITS) \\ e-mail: septi@na.its.ac.id
}

\begin{abstract}
Abstrak - Fitting yang tidak tepat pada penegar wrang pelat dan pembujur alas dalam menyebabkan terjadinya misalignmen. Misalignment tersebut diperbaiki dengan standard IACS sehingga penegar wrang pelat mengalami kemiringan. Dengan kemiringan yang terjadi pada penegar wrang pelat, tegangan yang terjadi pada sambungan wrang pelat dan pembujur alas dalam mengalami perubahan. Penelitian mengenai peningkatan tegangan akibat perbaikan yang dilakukan dibutuhkan agar perbaikan pada struktur dinyatakan aman. Perhitungan tegangan dilakukan dengan bantuan program elemen hingga. Variasi yang dilakukan adalah model konstruksi dengan misalignment pada penegar wrang pelat flatbar dan berprofil $\mathrm{L}$, lalu dibandingkan dengan model konstruksi tanpa misalignment. Hasil analisis menunjukan peningkatan tegangan akibat misalignment sebesar $4.864 \%$ pada konstruksi dengan penegar wrang pelat berpenegar flatbar dan $0.439 \%$ pada penegar wrang pelat profil $\mathrm{L}$. Peningkatan tegangan dan nilai tegangan terbesar terjadi pada penegar wrang pelat flatbar yaitu $4.864 \%$ dan 116.43 MPa. Tegangan yang terjadi pada model yang mengalami misalignment masih jauh di bawah tegangan ijin menurut Biro Klasifikasi Indonesia yaitu $230 \mathrm{MPa}$. Penegar wrang pelat dengan profil $L$ lebih menguntungkan secara kekuatan karena memiliki peningkatan tegangan yang lebih kecil dibanding flatbar.
\end{abstract}

Kata Kunci-Penegar Wrang Pelat, Misalignment, Analisis Tegangan, Metode Elemen Hingga.

\section{PENDAHULUAN}

$M$ ISALIGNMENT merupakan bagian dari proses pengerjaan yang buruk (bad workmanship) dan menjadi salah satu penyebab utama kelelahan pada struktur kapal. Misalignment juga menyebabkan konsentrasi tegangan tambahan pada struktur kapal. Misalignment pasti terjadi pada setiap kapal yang baru dibangun. Misalignment ini terjadi akibat human error maupun kesalahan akibat material yang berukuran tidak tepat. Pada galangan kapal baru, salah satu misalignment terjadi pada sambungan antara penegar wrang pelat dan pembujur alas dalam dan pembujur alas. Akibat fitting yang tidak tepat pada penegar wrang pelat dan pembujur, maka terjadi misalignment pada sambungan penegar wrang pelat dengan pembujur tersebut. Misalignment tersebut sering kali diatasi dengan menghilangkan las pada penegar wrang pelat sepanjang $300 \mathrm{~mm}$ dari pembujur alas dalam dan menggeser potongan penegar tadi pada tempat yang tepat sehingga penegar wrang pelat mengalami kemiringan. Dengan kemiringan dan misalignment yang terjadi pada penegar wrang pelat tersebut, tegangan yang terjadi pada sambungan wrang pelat dan pembujur alas dalam mengalami perubahan akibat beban muatan dan beban yang diakibatkan oleh gelombang.

\section{TINJAUAN PUSTAKA}

\section{A. Misalignment}

Misalignment pada pelat atau penegar merupakan sebuah kondisi ketidaklurusan antara sambungan. Pada penelitian ini, misalignment terjadi pada sambungan penegar wrang pelat (solid floor) dengan penegar alas dan penegar alas dalam. Misalignment akibat perbedaan ketebalan pelat struktur menyebabkan tegangan yang besar pada area sambungan las (welded joint) [1]. Misalignment pada pelat sisi menyebabkan peningkatan faktor intensitas tegangan sebesar dua kali lipat [2]. Sudut yang dialami oleh sebuah struktur akan mempengaruhi tegangan dan regangan yang terjadi pada struktur tersebut [3].

Misalignment merupakan bagian dari proses pengerjaan yang buruk (bad workmanship) dan menjadi salah satu penyebab utama kelelahan pada struktur kapal. Misalignment juga menyebabkan konsentrasi tegangan tambahan pada struktur kapal [4].

Misalignment yang terjadi pada penegar panel (panel stiffener) diperbaiki dengan melakukan penggeseran pada penegar panel. Penentuan panjang pembengkokan penegar wrang pelat didasari oleh standard yang diberikan IACS [5]. Kutipan Standar pembengkokkan yang diberikan oleh IACS terlihat pada Gambar 1.

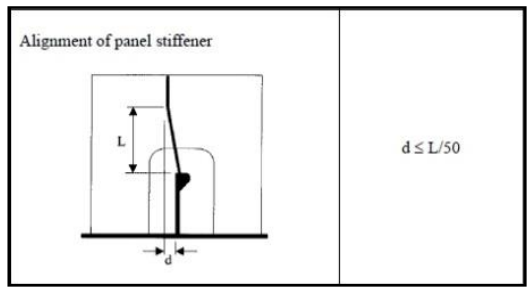

Gambar 1. Penentuan Panjang Pembengkokkan Penegar Panel.

\section{B. Metode Elemen Hingga}

Metode elemen hingga merupakan metode numerik untuk penyelesaian masalah rekayasa dan fisika matematis. Metode elemen hingga digunakan untuk menyelsaikan analisa struktur, perpindahan panas, aliran fluida, perpindahan massa, dan potensial elektromagnetik, serta menyelesaikan masalah dengan geometri yang sulit, dimana solusi analitis dirasa tidak mungkin dilakukan [6].

Pemilihan tipe elemen diutamakan bergantung pada tujuan dari analisis. Karakteristik elemen yang dipilih harus dapat merepresentasikan secara akurat terkait kekakuan dari sebuah struktur dan tegangan yang akan dianalisis. Ketika melakukan analisis tegangan, pengetahuan terkait karakteristik elemen harus memadai mengingat karakteristik elemen adalah sebuah prasyarat dari suatu pengerjaan analisis struktur [7]. 
Tujuan utama analisis dengan metode elemen hingga adalah memperoleh pendekatan tegangan dan perpindahan pada suatu struktur [8]. Pada beberapa kasus hasil perhitungan manual dan pendekatan elemen hingga berbeda, seperti pada analisis tegangan pada cross deck kapal ikan katamaran [9].

\section{B. Konvergensi Model}

Pada proses analisis struktur menggunakan metode elemen hingga (finite element method), terdapat tahapan dimana meshing. Salah satu komponen penting dalam meshing adalah konvergensi model dimana komponen tahapan ini bertujuan untuk memastikan bahwa ukuran elemen yang digunakan tidak berpengaruh terhadap hasil analisis [10].

Ukuran elemen berpengaruh terhadap tingkat keakurasian analisis elemen hingga. Semakin kecil ukuran elemen, maka semakin akurat pula tingkat keakurasian analisis elemen hingga tersebut. Penurunan ukuran elemen berarti meningkatkan jumlah elemen sehingga memakan lebih banyak waktu dan membutuhkan biaya komputasi yang lebih tinggi [4].

C. Tegangan Von Misses

Tegangan von misses merupakan kombinasi nilai seluruh tegangan pada sistem konstruksi. Tegangan von misses digunakan pada analisis tegangan material ulet (ductile). Analisis tegangan von misses mendefinisikan luluh (yield) sebagai kegagalan (failure), sehingga hasil yang didapatkan dari analisis tegangan von misses berupa nilai tegangan tarik pada konstruksi [11].

Besarnya nilai tegangan von misses dihitung dengan persamaan:

$\sigma v m=\sqrt{I_{1}^{2}-3 I_{2}}$

$I_{1}=\sigma_{x}+\sigma_{y}+\sigma_{z}$

$I_{2}=\sigma_{x} \sigma_{y}+\sigma_{y} \sigma_{z}+\sigma_{z} \sigma_{x}-\tau_{x z}^{2}-\tau_{y z}^{2}-\tau_{x y}^{2}$

(II.3)

Dimana,

$\mathrm{I}_{1} \quad=$ Stress Invariant 1

$\mathrm{I}_{2}=$ Stress invariant 2

$\sigma_{x} \quad=$ Tegangan normal pada sumbu $\mathrm{x}$

$\sigma y=$ Tegangan normal pada sumbu $\mathrm{y}$

$\sigma \mathrm{Z}=$ Tegangan normal pada sumbu $\mathrm{z}$

$\tau_{\mathrm{xz}}=$ Tegangan geser pada bidang $\mathrm{x}$ yang bekerja searah sumbu z

$\tau_{\mathrm{xz}}=$ Tegangan geser pada bidang $\mathrm{x}$ yang bekerja searah sumbu z

$\tau_{\mathrm{xz}}=$ Tegangan geser pada bidang $\mathrm{x}$ yang bekerja searah sumbu $\mathrm{z}$

Pada perhitungan tegangan dengan modulus profil yang sepadan, didapatkan nilai tegangan yang berbeda pada bentuk profil yang berbeda pada wing tank, sedangkan nilai tegangan berbanding lurus dengan nilai deformasi atau lenturan [12]. Lenturan dipengaruhi oleh beberapa faktor, antara lain modulus elastisitas, ukuran profil, tebal pelat, sistem konstruksi, dan jenis tumpuan [13].

\section{Pembebanan}

Pembebanan yang terjadi pada konstruksi alas serta konstruksi alas dalam merupakan beban dari muatan dan beban akibat gelombang sesuai peraturan Biro Klasifikasi
Indonesia. Pembebanan pada alas dalam akibat muatan dapat dirumuskan dalam rumus (II.4).

$\mathrm{Pi} \quad=9.81 \cdot \mathrm{G} / \mathrm{V} \cdot \mathrm{h}(1+\mathrm{av})$

Dimana,

$\mathrm{Pi} \quad=$ Tekanan pada konstruksi alas dalam akibat muatan $\left(\mathrm{kN} / \mathrm{m}^{2}\right)$

$\mathrm{G}=$ Berat muatan pada ruang muat $(\mathrm{kg})$

$\mathrm{V} \quad=$ Volume muatan pada ruang muat $\left(\mathrm{m}^{3}\right)$

$\mathrm{h}=$ Jarak dari batas bawah ruang muat sampai batas atas ruang muat $(\mathrm{m})$

av = Percepatan pergerakan muatan $\left(\mathrm{m} / \mathrm{s}^{2}\right)$

Pembebanan akibat gelombang pada alas kapal dapat dibagi menjadi dua yaitu dialami akibat gelombang dari arah depan atau belakang kapal dan beban akibat gelombang dari arah samping kapal. Dari kedua beban yang telah didapatkan, beban yang digunakan untuk menghitung konstruksi merupakan beban yang terbesar [14].

Beban yang dialami akibat gelombang dari arah depan atau belakang kapal dapat dirumuskan sebagai berikut:

$\mathrm{P}_{\mathrm{B}} \quad=10 \cdot \mathrm{T} \cdot \mathrm{Po} \cdot \mathrm{C}_{\mathrm{f}}$

Dimana,

$\mathrm{P}_{\mathbf{B}} \quad=$ Beban akibat gelombang dari arah depan atau belakang kapal $\left(\mathrm{kN} / \mathrm{m}^{2}\right)$

$\mathrm{T}=$ Sarat scantling kapal $(\mathrm{m})$

Po $\quad=$ Beban dinamis kapal dari arah depan atau belakang kapal $\left(\mathrm{kN} / \mathrm{m}^{2}\right)$

$\mathrm{C}_{\mathrm{f}} \quad=$ Faktor lokasi pembebanan kapal

Beban yang dialami akibat gelombang dari arah samping kapal dapat dirumuskan sebagai berikut:

$\mathrm{P}_{\mathrm{B} 1} \quad=10 \cdot \mathrm{T} \cdot \mathrm{P}_{\mathrm{O} 1} \cdot 2 \cdot(|\mathrm{y}|) / \mathrm{B}$

Dimana,

$\mathrm{P}_{\mathrm{B} 1}=$ Beban akibat gelombang dari arah samping kapal $\left(\mathrm{kN} / \mathrm{m}^{2}\right)$

$\mathrm{T}=$ Sarat scantling kapal $(\mathrm{m})$

$\mathrm{P}_{\mathrm{O} 1}=$ Beban dinamis kapal dari arah samping kapal $\left(\mathrm{kN} / \mathrm{m}^{2}\right)$

$\mathrm{y}=$ = Jarak antara centerline dan titik terluar dari alas (m) B $\quad=$ Lebar kapal $(\mathrm{m})$

E. Tegangan Ijin

Tegangan ijin merupakan tegangan yang tidak boleh dilampaui sebuah sistem struktur, dimanapun letaknya akibat faktor keamanan [15]. Secara umum tegangan ijin dirumuskan seperti pada rumus (II.7).

Tegangan Ijin $=\frac{\text { Tegangan Luluh }}{\text { Faktor Keamanan }}$

Pada rumus (II.7), semakin tinggi faktor keamanan, semakin rendah juga tegangan ijin dari struktur. Faktor keamananan harus lebih besar dari 1.0 agar tegangan luluh dari material struktur tidak terlampaui.

Menurut Biro Klasifikasi Indonesia, tegangan ijin pada struktur alas dalam kapal dirumuskan pada rumus (II.10)

$\sigma v=\frac{230}{k}$

$k=\frac{235}{\operatorname{ReH}}$

Dimana, 
$\sigma_{\mathrm{y}} \quad=$ Tegangan ijin $(\mathrm{MPa})$

$\mathrm{k}=$ faktor material

$\mathrm{R}_{\mathrm{eH}} \quad=$ Titik luluh material $(\mathrm{MPa})$

Pada rumus (II.9), disebutkan sebuah faktor yaitu $\mathrm{R}_{\mathrm{eH}}$ yang merupakan titik luluh material. Pada aturan Biro Klasifikasi Indonesia bahwa nilai $\mathrm{R}_{\mathrm{eH}}=235 \mathrm{MPa}$ untuk jenis material baja struktur kekuatan normal. Baja struktur yang termasuk kedalam kategori baja struktur kekuatan normal adalah baja dengan grade KI-A, KI-B, KI-D, dan KI-E [14].

\section{METODOLOGI PENELITIAN}

\section{A. Data Kapal}

Data kapal yang digunakan adalah kapal Crude Oil Tanker 10.000 DWT dengan keterangan dimensi utama ditujunjukan pada Tabel 1.

Tabel 1.

Ukuran Utama Kapal Crude Oil Tanker 10.000 DWT PRINCIPLE DIMENSIONS

\begin{tabular}{ccc}
\hline \multicolumn{3}{c}{ PRINCIPLE DIMENSIONS } \\
\hline SHIP TYPE & OIL TANKER & \\
LENGTH OVER ALL (Loa) & 114.4 & $\mathrm{~m}$ \\
LENGTH BETWEEN PERPENDICULARS & 110.0 & $\mathrm{~m}$ \\
BREADTH (B) & 20.0 & $\mathrm{~m}$ \\
HEIGHT (H) & 10.4 & $\mathrm{~m}$ \\
DRAUGHT (T) & 8.0 & $\mathrm{~m}$ \\
SERVICE SPEED (Vs) & 14.0 & Knots \\
COMPLEMENT & 24.0 & Persons \\
\hline \hline
\end{tabular}

Selain data ukuran utama kapal, gambar penampang melintang dibutuhkan dalam pembuatan model alas dalam. Untuk menjaga agar tidak terjadi bias pada saat pembacaan hasil, model yang digunakan hanya pada alas dalam, dengan panjang $3 \mathrm{~m}$ (sejarak gading besar), serta dengan lebar $4 \mathrm{~m}$ (jarak antar dua side girder).

\section{B. Beban Pada Struktur Kapal dan Tegangan Ijin}

Berdasarkan hasil perhitungan dengan menggunakan rumus (II.4) sampai (II.6), beban pada alas dalam kapal akibat muatan adalah $84.69 \mathrm{kN} / \mathrm{m}^{2}$, sedangkan beban pada alas kapal akibat gelombang adalah $99.16 \mathrm{kN} / \mathrm{m}^{2}$. Perhitungan dilakukan dengan menggunakan ukuran utama kapal. Rumus (II.8) dan (II.9) menunjukan bahwa tegangan ijin pada struktur sebesar $230 \mathrm{MPa}$.

\section{Pembuatan Model Konstruksi}

Terdapat empat model konstruksi yang akan dibuat pada penelitian ini, yaitu model konstruksi dengan penegar wrang pelat flatbar tanpa misalignment, model konstruksi dengan penegar wrang pelat flatbar dengan misalignment, model konstruksi dengan penegar wrang pelat berprofil L tanpa misalignment, serta model konstruksi dengan penegar wrang pelat berprofil L dengan misalignment. Jarak misalignment yang digunakan adalah $10 \mathrm{~mm}$ sehingga panjang las-lasan yang dihilangkan adalah $500 \mathrm{~mm}$. Pembuatan model konstruksi dilakukan dengan bantuan software AutoCAD.

\section{Meshing Pada Model Konstruksi}

Setelah model geometri diimpor ke dalam program elemen hingga, proses meshing dapat dilakukan dengan program elemen hingga. Pada proses meshing, sifat mekanis dari bahan juga diberikan. Sifat bahan yang diberikan adalah baja karbon yang sesuai dengan aturan Biro Klasifikasi Indonesia Grade KI-A dengan kuat luluh sebesar $235 \mathrm{~N} / \mathrm{mm}^{2}$ serta kuat ultimate sebesar 400-520 N/mm² [16].

\section{E. Konvergensi Model}

Pada model konstruksi dengan penegar wrang pelat flatbar, baik dengan misalignment maupun tanpa misalignment, konvergensi model dilakukan mulai pada ukuran elemen $0.088 \mathrm{~m}$ sampai $0.085 \mathrm{~m}$. Khusus pada penegar wrang pelat, ukuran elemen yang digunakan adalah $0.025 \mathrm{~m}$.

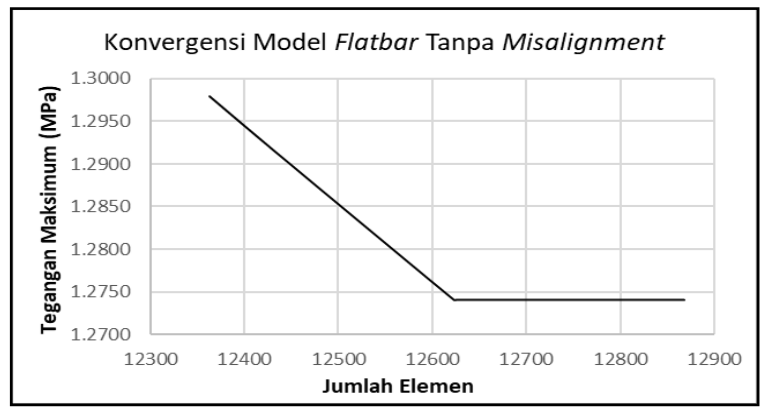

Gambar 2. Konvergensi model flatbar tanpa misalignment.

Pada Gambar 2., model konstruksi penegar wrang pelat flatbar tanpa misalignment, model konvergen pada jumlah elemen sekitar 12620 elemen sampai seterusnya, ukuran elemen yang dipakai adalah $0.086 \mathrm{~m}$ dengan jumlah elemen sebanyak 12623 elemen.

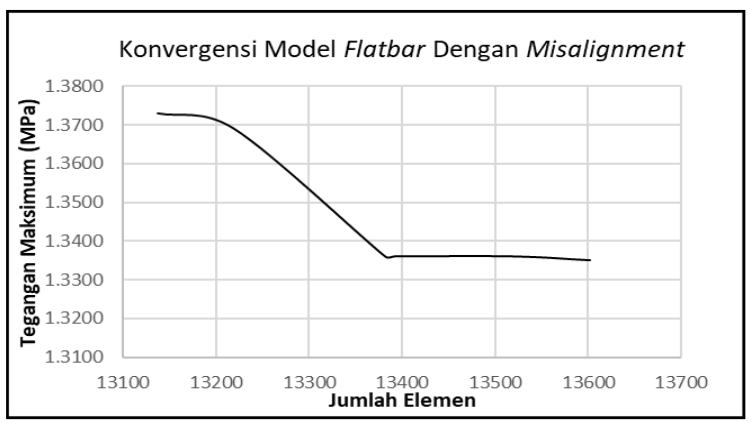

Gambar 3. Konvergensi model flatbar dengan misalignment.

Pada Gambar, model konstruksi penegar wrang pelat flatbar dengan misalignment, model konvergen pada jumlah elemen sekitar 13400 elemen sampai seterusnya. Ukuran elemen yang dipakai adalah $0.086 \mathrm{~m}$ dengan jumlah elemen sebanyak 13382 elemen.

Pada model konstruksi penegar wrang pelat berprofil L, konvergensi model dilakukan mulai pada ukuran elemen 0.104 sampai $0.101 \mathrm{~m}$. Khusus pada penegar wrang pelat, ukuran elemen yang digunakan adalah $0.025 \mathrm{~m}$.

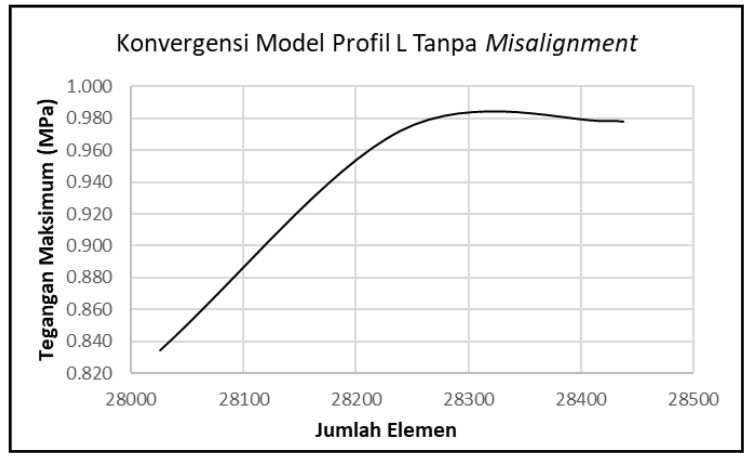

Gambar 4. Konvergensi model profil L tanpa misalignment 


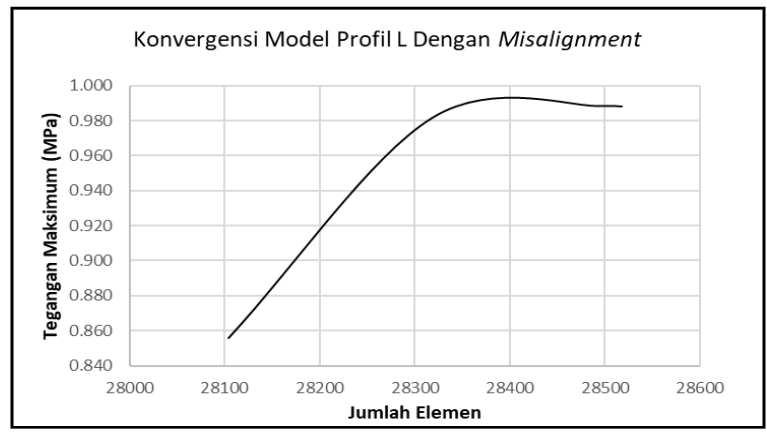

Gambar 5. Konvergensi model profil L dengan misalignment.

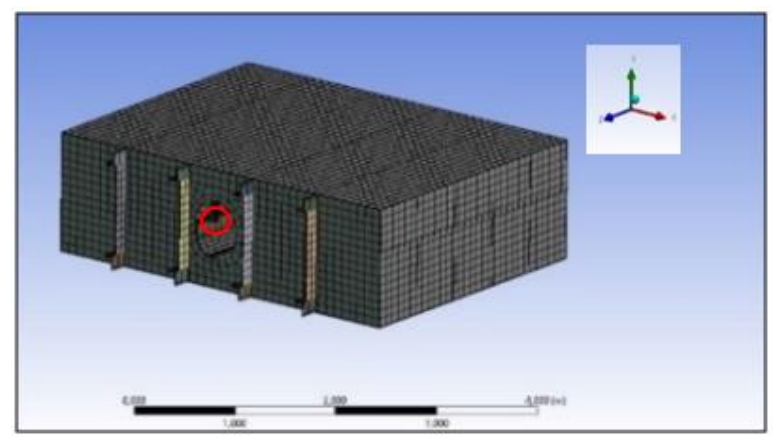

Gambar 6. Titik Tinjau Pembacaan Tegangan.

Pada Gambar, model konstruksi dengan penegar wrang pelat berprofil L tanpa misalignment, model konvergen pada ukuran elemen sekitar $0.102 \mathrm{~m}$ dengan jumlah elemen sebanyak 28422 elemen sampai seterusnya, ukuran elemen yang dipakai adalah $0.102 \mathrm{~m}$ dengan ukuran elemen sebanyak 28422 elemen.

Pada Gambar, model konstruksi dengan penegar wrang pelat berprofil $\mathrm{L}$ dengan misalignment, model konvergen pada ukuran elemen $0.102 \mathrm{~m}$ dengan jumlah elemen sebanyak 28498 elemen sampai seterusnya, ukuran elemen yang dipakai adalah $0.102 \mathrm{~m}$ dengan ukuran elemen sebanyak 28498 elemen.

\section{F. Pembebanan Pada Model Konstruksi}

Pembebanan pada model konstruksi dilakukan dengan program elemen hingga. Peletakan beban dilakukan pada pelat alas dalam model. Titik tinjau yang diinginkan adalah sambungan antara penegar wrang pelat yang dibengkokkan dengan pembujur alas dalam. Posisi titik tinjau ditunjukkan

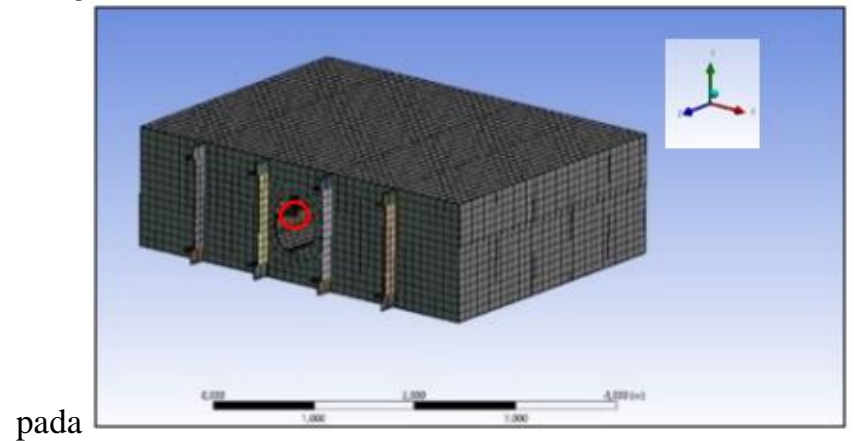

Gambar .

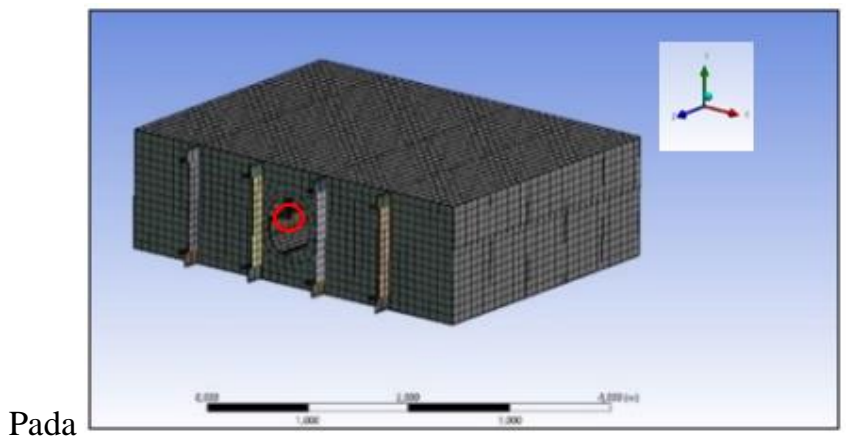

Gambar, titik tinjau ditunjukkan dengan lingkaran merah yaitu pada sambungan antara pembujur alas dalam dengan penegar wrang pelat yang akan dibengkokkan.

\section{IV.HASIL DAN ANALISIS DATA}

\section{A. Model Flatbar Tanpa Misalignment}

Pada model pofil I tanpa misalignment, besar tegangan pada titik tinjau adalah $111.03 \mathrm{MPa}$. Hasil pembacaan tegangan ditunjukkan pada Error! Reference source not found.

\section{B. Model Flatbar Dengan Misalignment}

Pada model flatbar dengan misalignment, tegangan maksimum terjadi tepat pada lokasi tinjau yang diinginkan. Besar tegangan pada titik tinjau adalah 116.43 MPa. Hasil

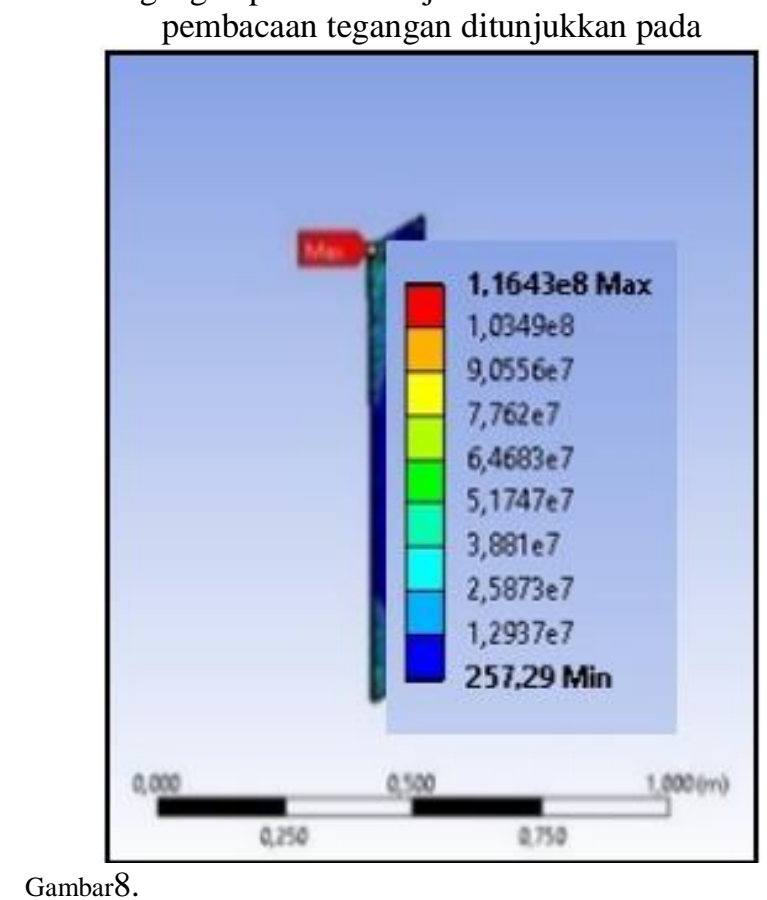

Gambar8.

\section{Model Profil L Tanpa Misalignment}

Pada model profil L tanpa misalignment, besar tegangan pada titik tinjau adalah 86.077 MPa. Hasil pembacaan tegangan 


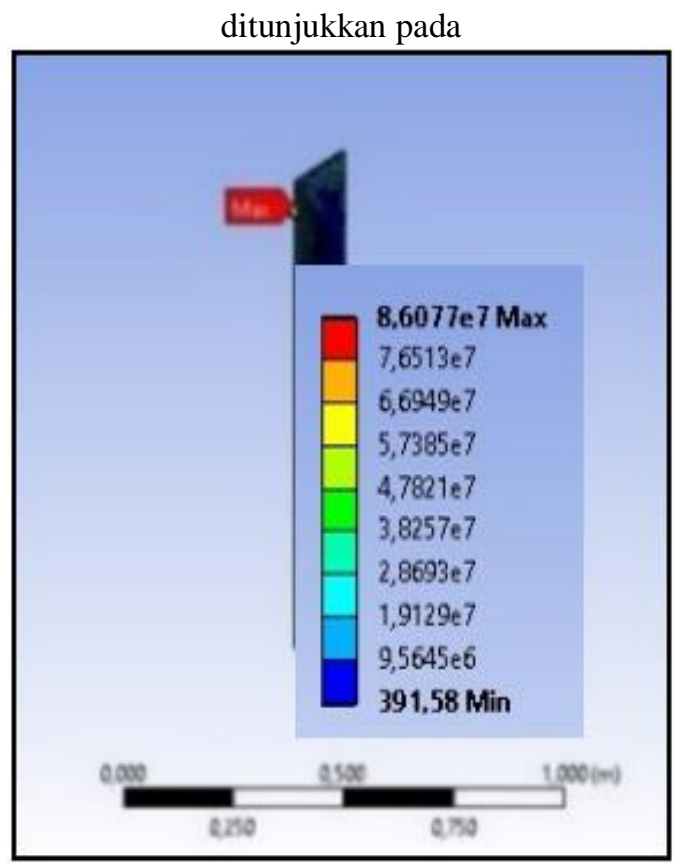

Gambar9.

\section{Model Profil L Dengan Misalignment}

Pada model profil L dengan misalignment, besar tegangan pada titik tinjau adalah $86.455 \mathrm{MPa}$. Hasil pembacaan tegangan ditunjukkan pada

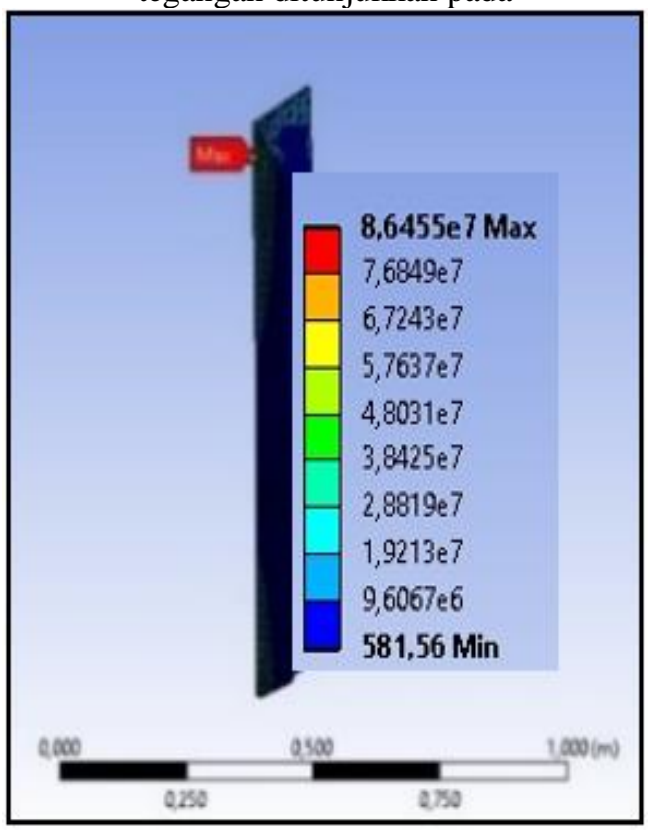

Gambar10.

\section{E. Perbandingan Hasil Analisis Pada Model Flatbar}

Pada sub-bab sebelumnya dijelaskan hasil analisis pada model konstruksi flatbar, baik dengan misalignment maupun tanpa misalignment. Hasil perbandingan ditunjukkan pada Tabel2.

Tabel 2.

Perbandingan Tegangan Model Flatbar

\begin{tabular}{lll}
\hline \hline No & Keterangan & Tegangan (MPa) \\
\hline 1 & Model Tanpa Misalignment & 111.03 \\
2 & Model Dengan Misalignment & 116.43 \\
\hline \hline
\end{tabular}

Tabel2 menunjukan bahwa terjadi peningkatan tegangan bila terjadi misalignment sebesar $5.4 \mathrm{MPa}$. Peningkatan yang terjadi pada penegar wrang pelat yang mengalami pembengkokkan akibat misalignment sebesar $4.864 \%$

\section{F. Perbandingan Hasil Analisis Pada Model Profil L}

Pada sub-bab sebelumnya dijelaskan hasil analisis pada model konstruksi profil L, baik dengan misalignment maupun tanpa misalignment. Hasil perbandingan ditunjukkan pada Tabel3.

Tabel 3.

Perbandingan Tegangan Model Profil L

\begin{tabular}{ccc}
\hline \hline No & Keterangan & Tegangan (mpa) \\
\hline 1 & Model Tanpa Misalignment & 86.077 \\
2 & Model Dengan Misalignment & 86.455 \\
\hline \hline
\end{tabular}

Tabel3 menunjukan bahwa terjadi peningkatan tegangan bila terjadi misalignment sebesar $0.378 \mathrm{MPa}$. Peningkatan yang terjadi pada penegar wrang pelat yang mengalami pembengkokkan akibat misalignment sebesar $0.439 \%$.

\section{G. Perbandingan Hasil Analisis Model Profil L dan Flatbar}

Perbedaan peningkatan tegangan yang terjadi pada model dengan flatbar dengan model berprofil L diakibatkan oleh pelat face yang ada pada penegar wrang pelat dengan profil L. Dengan momen inersia terhadap neutral axis dan modulus profil sepadan namun keberadaan pelat face pada profil L mempengaruhi luas penampang melintang profil, yaitu 18.8 $\mathrm{cm}^{3}$ pada flatbar dan $24 \mathrm{~cm}^{3}$ pada profil L. Pada penegar wrang pelat profil $\mathrm{L}$, sambungan antara penegar wrang pelat dengan pembujur alas dalam tidak terletak pada pelat face pembujur alas dalam namun terletak pada pelat bilah pembujur alas dalam. Sedangkan da penegar wrang pelat dengan flatbar, sambungan terletak pada pelat face pembujur alas dalam. 


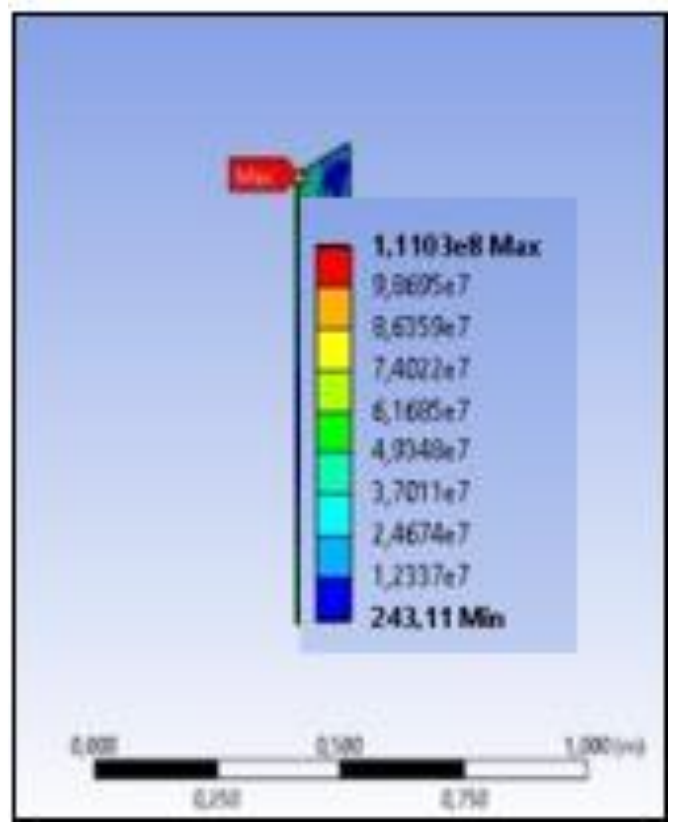

Gambar 7. Hasil Pembacaan tegangan.

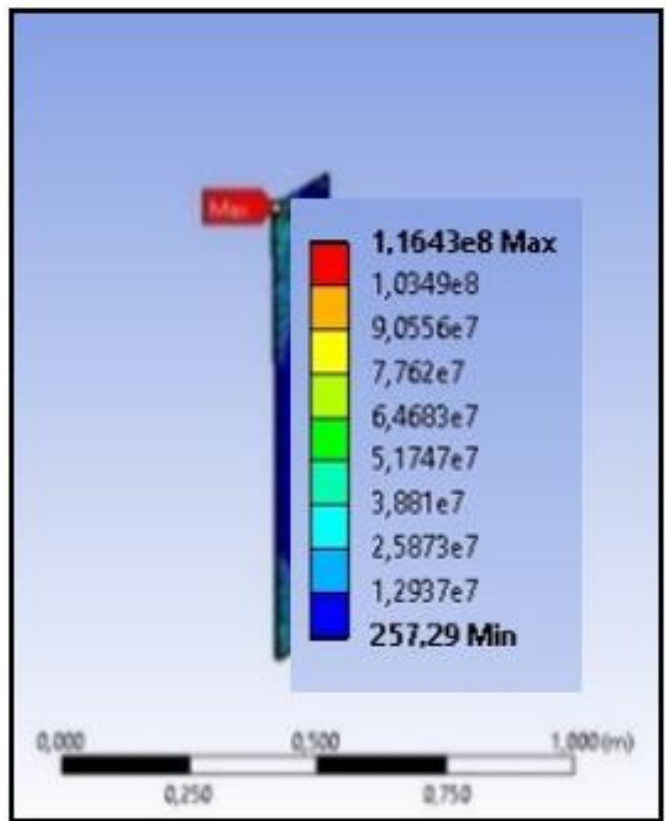

Gambar 8. Hasil Pembacaan tegangan.

\section{KESIMPULAN DAN SARAN}

\section{A. Kesimpulan}

Setelah dilakukan simulasi perhitungan menggunakan program elemen hingga, kesimpulan yang didapatkan dari penelitian ini adalah sebagai berikut:

1. Pada model dengan flatbar pada penegar wrang pelat, menghasilkan nilai tegangan sebesar $116.43 \mathrm{MPa}$ pada kejadian misalignment, sedangkan tanpa kejadian misalignment menghasilkan nilai tegangan sebesar 111.43 Mpa dengan peningkatan tegangan sebesar $4.864 \%$

2. Pada model dengan profil L pada penegar wrang pelat, menghasilkan nilai tegangan sebesar $86.455 \mathrm{MPa}$ pada kejadian misalignment, sedangkan tanpa kejadian

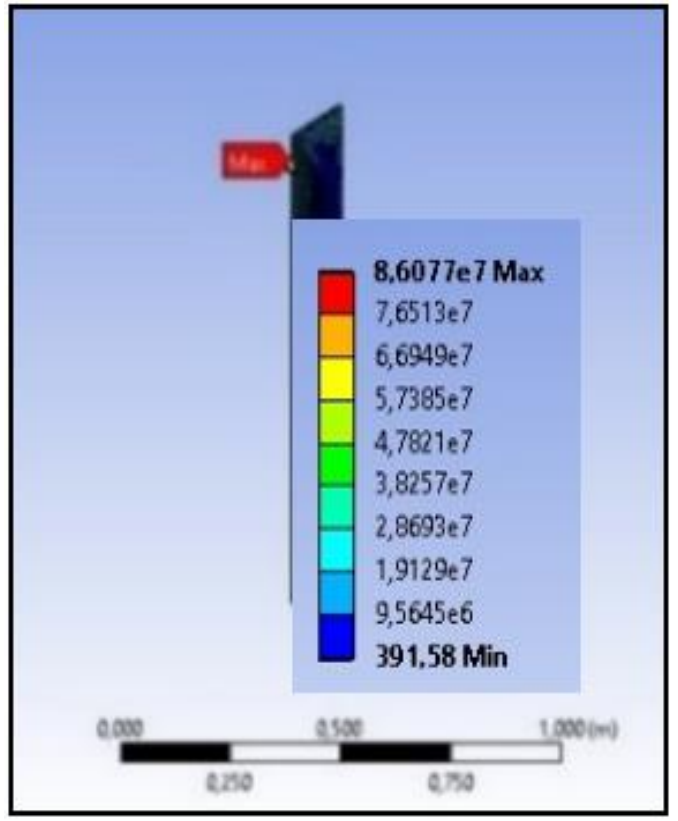

Gambar 9. Hasil Pembacaan tegangan.

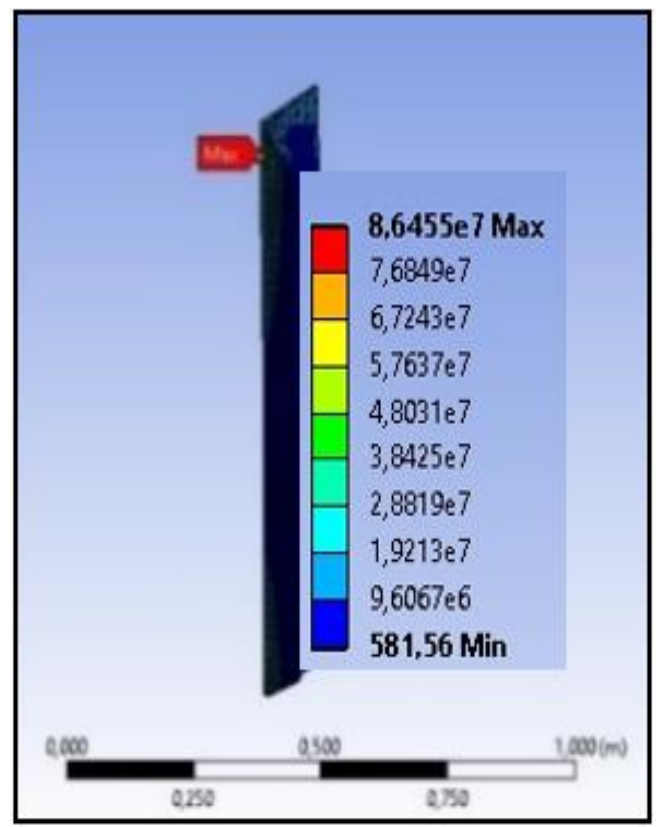

Gambar 10. Hasil Pembacaan tegangan.

misalignment menghasilkan nilai tegangan sebesar 86.077 MPa dengan peningkatan tegangan sebesar $0.439 \%$

3. Peningkatan tegangan terbesar dan nilai tegangan terbesar terjadi pada model dengan wrang pelat berpenegar flatbar yaitu $4.864 \%$ dan $116.43 \mathrm{MPa}$.

4. Profil L lebih menguntungkan secara kekuatan sebagai penegar wrang pelat karena profil L memiliki peningkatan tegangan yang lebih kecil dibanding flatbar pada kejadian misalignment.

\section{B. Saran}

Berdasarkan metodologi, hasil, serta kesimpulan yang didapatkan dari penelitian ini, terdapat beberapa saran yang didapatkan, yaitu: 
1. Perhitungan umur struktur akibat kelelahan atau fatigue diperlukan sebagai tindak lanjut dari peningkatan tegangan yang terjadi.

2. Penggunaan Profil L sebagai penegar wrang pelat lebih disarankan karena memiliki tegangan yang lebih kecil dengan peningkatan tegangan yang lebih kecil akibat pembengkokan pada kasus misalignment.

\section{DAFTAR PUSTAKA}

[1] Liu and et al, "Misalignment Effect On Stress Concentration of Thickness Mismatched Plate Structures," in 21st European Conferences on Fracture, 2016.

[2] A. Rudin and M. N. Misbah, "Analisis Fatigue Life Struktur Akibat Misalignment Pada Sambungan Pelat," J. Tek. POMITS, vol. 1, no. $1,2012$.

[3] D. Roylance, "Transformation Of Stresses and Strains," Cambridge, 2001.

[4] O. F. Hughes and J. K. Paik, "Ship Structural Analysis and Design," 2010.

[5] International Association of Classification Societies, "Recommendation No. 47 Shipbuilding and Repair Quality Standard," 2010.

[6] D. L. Logan, A First Course in The Finite Element Method.
Platteville: University of Wisconsin, 2005.

[7] Biro Klasifikasi Indonesia, “Analysis Techniques Strength,” 2005.

[8] D. S. Ardianus and H. Sujiatanti, "Analisis Kekuatan Konstruksi Sekat Melintang Kapal Tanker Dengan Metode Elemen Hingga," $J$. Tek. POMITS, vol. 6, no. 2, 2017.

[9] I. Chabibi, K. Suastika, and T. Yulianto, "Analisa Tegangan Pada Cross Deck Kapal Ikan Katamaran 10 GT Menggunakan Metode Elemen Hingga," J. Tek. POMITS, vol. 2, no. 1, 2013.

[10] NAFEMS, "The Importance of Mesh Convergence - 1," 2018.

[11] I.-C. Jong and W. Springer, "Teaching Von Misses Stress: From Principal Axes To Nonprincipal Axes," Arkansas, 2009.

[12] D. D. Sanjaya, S. H. Sujiatanti, and T. Yulianto, "Analisa kekuatan konstruksi wing tank kapal tanker menggunakan metode elemen hingga," J. Tek. ITS, vol. 6, no. 2, pp. G277-G281, Sep. 2017.

[13] T. Putranto and A. Imron, "Analisis Pengaruh Variasi Jarak Gading Terhadap Lenturan dan Tegangan Pada Pelat Sisi dengan Metode Elemen Hingga," J. Tek. POMITS, vol. 1, no. 1, 2012.

[14] Biro Klasifikasi Indonesia, "Rules For The Classification and Construction Part 1 Seagoing Ships Volume II RUles For Hull," 2014.

[15] M. Gere and S. P. Timoshenko, Mekanika Bahan Jilid 1. Jakarta: Erlangga, 2000.

[16] Biro Klasifikasi Indonesia, "Rules For Classification And Construction Part 1 Seagoing Ships Volume V Rules For Materials," 2017. 